\title{
Strategi Komunikasi Pemasaran Qoo10 Indonesia Mempertahankan Eksistensi
}

\author{
Julita Esther I.D.S ${ }^{1}$, Adi Wiratama ${ }^{2}$ \\ ${ }^{1,2}$ Program Sarjana Ilmu Komunikasi \\ Sekolah Tinggi Ilmu Komunikasi Indonesia Maju \\ Jln. Harapan Nomor 50, Lenteng Agung - Jakarta Selatan 12610 \\ Telp: (021) 78894045, Email: irenedossantos07@gmail.com,wiratamaadi08@gmail.com
}

\begin{abstract}
Abstrak
Kemajuan teknologi informasi, khususnya Internet hampir merubah semua bidang, salah satunya dunia bisnis. Perubahan cara pandang dalam berbisnis ini yang ikut mendukung timbulnya perusahaan e-commerce, dan salah satunya adalah Qoo10. Penelitian ini bertujuan untuk (1) mengetahui strategi komunikasi pemasaran perusahaan, (2) mengetahui bentuk-bentuk komunikasi pemasara perusahaan, dan (3) melihat latarbelakang pemilihan strategi komunikasi pemasaran tersebut. Penelitian ini bersifat kualitatif dengan pendekatan deskriptif evaluatif karena lebih memfokuskan pada aspek kealamiahan data. Pengumpulan data dilakukan dengan cara (1) penelitian perpustakaan, (2) wawancara mendalam dengan informan kunci yang bertujuan untuk memperoleh perspektif tentang strategi komunikasi pemasaran serta sejauh mana pemanfaatan dari fasilitas-fasilitas yang ada pada $B 2 B$ (Bussiness to Bussiness) e-commerce, dan (3) penelitian lapangan. Untuk menganalisa suatu strategi komunikasi pemasaran, dipengaruhi oleh banyak faktor, yaitu (1) faktor ekstemal dan intemal perusahaan diperlukan untuk menganalisa kekuatan, kelemahan, peluang dan ancaman pada suatu perusahaan atau SWOT analisis, (2) pemilihan target pasar, segmentasi dan memposisikan produk perusahaan atau STP, (3) bauran pemasaran yang digunakan atau marketing mix, (4) promotion mix atau communication tools yang dipergunakan. Berdasarkan hasil wawancara dan penelitian dilapangan, ditemukan bahwa, pentingnya strategi komunikasi pemasaaran yang didukung oleh perencanaan dan strategi pemasaran dengan menganalisis lingkungan (faktor internal dan eksternal). Peranan strategi komunikasi pemasaran yang dihasilkan melalui situasi dan kondisi perusahaan dapat membuat suatu perusahaan tetap eksis dan dapat terus meningkatkan keunggulan dalam bidang bisnisnya.
\end{abstract}

Kata Kunci : E-Commerce, Komunikasi Pemasaran, Strategi

\begin{abstract}
Advances in information technology, especially the Internet almost changed all areas, one of which the business world. Changes in the way of view in this business that helped support the emergence of e-commerce companies, and one of them is Qool0. This study aims to (1) know the company's marketing communications strategy, (2) to know the forms of corporate marketing communications, and (3) to see the background of the selection of marketing communication strategy. This research is qualitative with evaluative descriptive approach because it focuses more on the aspect of data. Data collection is done by (1) library research, (2) in-depth interviews with key informants aimed at obtaining perspectives on marketing communications strategy as well as the extent of utilization of existing facilities in B2B (Business to Business) e-commerce, and (3) field research. To analyze a marketing communications strategy, it is influenced by many factors, namely (1) external and internal factors are needed to analyze strengths, weaknesses, opportunities and threats to a company or SWOT analysis, (2) selection of target market, segmentation and positioning of company product or STP, (3) marketing mix used or marketing mix, (4) promotion mix or communication tools used. Based on the results of interviews and research in the field, it was found that the importance of the marketing communication strategy supported by planning and marketing strategy by analyzing the environment (internal and external factors). The role of marketing communications strategy generated through the situation and condition of the company can make a company still exist and can continue to improve excellence in the field of busines.
\end{abstract}

Keywords : E-Commerce, Marketing Communication, Strategy. 


\section{Jurnal Ilmiah Komunikasi}

\section{Pendahuluan}

Perkembangan bisnis online memang sangat pesat saat ini. Internet yang sudah dapat diakses hampir seluruh orang di dunia hingga ke pelosok ini telah memudahkan kita untuk mencari informasi sampai sedetil-detilnya. ${ }^{1}$

Dengan bantuan teknologi, aktivitas seharihari pun semakin mudah, termasuk berbelanja. Saat ini ada ratusan perusahaan rintisan berbasis belanja online yang menyediakan jasa dengan berbagai promosi. Pengguna internet tinggal memilih jasa layanan belanja online mana yang ingin ia gunakan, tentu berdasarkan atribusi yang diberikan perusahaan $e$-commerce tersebut seperti persaingan harga, layanan, keamanan, dll.

E-Commerce (Electronic Commerce) adalah penjualan atau pembelian barang dan jasa, antara perusahaan, rumah tangga, individu, pemerintah, dan masyarakat atau organisasi swasta lainnya, yang dilakukan melalui komputer pada media jaringan. Barang-barang dan jasa dapat dipesan melalui jaringan tersebut, tetapi pembayaran dan pengiriman barang atau jasa dapat dilakukan di akhir atau offline. E-commerce dicari untuk menambahkan aliran pendapatan dengan menggunakan internet untuk membangun hubungan dengan klien dan mitra usaha. Terkadang e-commerce melibatkan aplikasi dari sistem manajemen pengetahuan.

Semakin besar ekosistem e-commerce di Indonesia, penggunanya pun semakin luas dan loyal. Selayaknya peribahasa "semakin tinggi pohon, maka semakin kencang angin yang menerpa" ini juga berlaku bagi para pelaku bisnis e-commerce. Beragam tantangan harus dihadapi demi menjaga kestabilan perusahaan yang bermuara dari kepuasan konsumen.

E-commerce terbagi atas dua segmen yaitu perdagangan antar pelaku usaha (business to business e-commerce) dan perdagangan antar pelaku usaha dengan konsumen (business to consumer e-commerce). Segmen business to business e-commerce memang lebih mendominasi pasar saat ini karena nilai transaksinya yang tinggi, namun level business to consumer e-commerce juga memiliki pangsa pasar tersendiri yang potensial. Online store belakangan ini semakin berkembang, sejalan dengan semakin berkembangnya masyarakat yang memiliki komputer serta akses ke internet dan perkembangan teknologi yang sangat pesat. Perkembangan ini mendorong para penjual produk konvensional ikut memasarkan produknya melalui internet.

E-commerce dicari untuk menambahkan aliran pendapatan dengan menggunakan internet untuk membangun hubungan dengan klien dan mitra usaha. Terkadang e-commerce melibatkan aplikasi dari sistem manajemen pengetahuan. ${ }^{2}$

Dalam dunia digital di Indonesia, sektor $e$ commerce telah menjadi primadona. Fenomena ini ditunjukkan dengan tak hanya menjamurnya toko-toko online lokal, namun juga invasi pemain e-commerce besar dari luar negeri yang masuk ke Indonesia. Alasan utama yang sering dijadikan alasan pemain luar untuk memperluas jaringan ke Indonesia, adalah pasar yang besar. Dengan jumlah populasi yang besar dan pengguna ponsel yang terus meningkat, memberikan peningkatan yang berarti pada individu yang online secara aktif. Ini juga disinyalir menjadi sebuah pergeseran gaya hidup, saat ini orang memenuhi kebutuhan dengan belanja online.

Perkembangan bisnis e-commerce atau jual beli online di Indonesia meningkat drastis sejak beberapa tahun belakangan. Hal ini karena Indonesia sebagai salah satu negara dengan pengguna internet terbesar di dunia. Data dari Social Research \& Monitoring soclab.co menunjukkan, pada 2015 pengguna internet di Indonesia mencapai 93,4 juta dengan 77 persen di antaranya mencari informasi produk dan belanja online. Pada 2016, jumlah online shopper mencapai 8,7 juta orang dengan nilai transaksi sekitar 4,89 miliar dolar AS atau sekitar 670 triliun rupiah. ${ }^{3}$

Pertumbuhan pesat pangsa pasar $e$ commerce di Indonesia memang sudah tidak bisa diragukan lagi. Dengan jumlah pengguna internet yang mencapai angka 82 juta orang atau sekitar 30\% dari total penduduk di Indonesia, pasar e-commerce menjadi tambang emas yang sangat menggoda bagi sebagian orang yang bisa melihat potensi ke depannya. 


\section{Jurnal Ilmiah Komunikasi}

Ini merupakan angka yang sangat fantastis mengingat bahwa hanya sekitar $7 \%$ dari pengguna internet di Indonesia yang pernah belanja secara online, ini berdasarkan data dari McKinsey. Dibandingkan dengan China yang sudah mencapai $30 \%$, Indonesia memang masih tertinggal jauh, tapi perlu diingat bahwa jumlah ini akan terus naik seiring dengan bertumbuhnya penggunaan smartphone, penetrasi internet di Indonesia, penggunaan kartu debit dan kredit, dan tingkat kepercayaan konsumen untuk berbelanja secara online. Jika kita melihat Indonesia sebagai Negara kepulauan yang sangat luas, e-commerce adalah pasar yang berpotensi tumbuh sangat besar di Indonesia.

Sudah semakin banyak kota-kota kecil di Indonesia yang mulai berbelanja secara online. Pada tahun 2012, suatu perusahaan e-commerce di Indonesia mencatat bahwa $41 \%$ penjualan mereka berasal dari Jakarta, tapi enam bulan selanjutnya angka ini turun menjadi $22 \%$. $^{4}$ Ini menunjukkan bahwa tidak hanya konsumen di Jakarta saja yang rutin berbelanja online, konsumen di luar Jakarta pun tidak ingin ketinggalan mengikuti perkembangan zaman dengan menunjukkan kontribusi mereka pada pasar e-commerce di Indonesia.

Data dari lembaga riset ICD memprediksi bahwa pasar e-commerce di Indonesia akan tumbuh $70 \%$ dari tahun 2015-2020. Angka ini lebih tinggi jika dibandingkan negara lain seperti Malaysia (14\%), Thailand (22\%), dan Filipina (28\%). Tentulah nilai sebesar ini sangat menggoda bagi sebagian investor, baik dalam maupun luar negeri. Beberapa VC (Venture Capital) besar seperti Rocket Internet, CyberAgent, East Ventures, dan IdeoSource bahkan sudah menanamkan modal ke perusahaan e-commerce yang berbasis di Indonesia. Sebut saja beberapa diantaranya adalah raksasa Lazada dan Zalora, Berrybenka, Tokopedia, Bilna, Saqina, VIP Plaza, Ralali dan masih banyak lagi. Mereka adalah sebagian contoh dari perusahaan e-commerce yang sukses dan berhasil dalam memanfaatkan peluang pasar e-commerce di Indonesia yang sedang naik daun.

Saat ini berbelanja secara online bukan hanya menjadi alternatif membeli barang. Saat ini kegiatan tersebut telah menjadi gaya hidup sebagian masyarakat. Tak sedikit pula yang sudah kecanduan atau menganggapnya sebagai sebuah kebiasaan. Meski masih banyak orang yang tidak percaya dengan online shopping, industri ini terus saja berkembang. Bahkan menurut data yang dihimpun oleh BMI Research, di tahun 2018 kegiatan berbelanja melalui e-commerce akan meningkat dua kali lipat dan bisa menyumbangkan Rp 100 triliun untuk negara.

Data yang dilansir dari situs BMI (Brand \& Marketing Institute) (http://www.bmiresearch.com/ tercatat bahwa wanita menempati urutan pertama gemar berbelanja online dengan presentase $58 \%$, dan diikuti pria dengan presentasi $47 \%$. Untuk mendalami dan mempelajari fenomena ini, BMI Research telah melakukan penelitian di 10 kota besar di Indonesia melalui phone survey. Hasilnya yang paling berminat belanja online adalah perempuan dengan angka mencapai $58 \%$, dan $56 \%$ berusia antara 18-30 tahun, sedangkan dari sisi remaja 18-23 tahun yaitu pelajar dan mahasiswa.

Tidak hanya itu, banyaknya wanita yang gemar belanja online juga terlihat dari hasil penjualan produk favorit. Kategori fashion menduduki urutan pertama dengan jumlah $41 \%$ lalu kosmetik di tempat kedua dengan jumlah $40 \%$.

Perkembangan teknologi saat ini justru seolah makin mendukung hobi belanja kaum wanita. Bagaimana tidak? Pergeseran model transaksi dari offline menjadi online semakin memberi kemudahan bagi para wanita untuk berbelanja. Hanya dengan duduk di depan laptop atau memegang gadget, belanja bisa dilakukan dengan sekali sentuh. Kebanyakan wanita mudah 'lapar mata', sehingga mereka cenderung membutuhkan waktu cukup lama bisa sampai berjam-jam untuk belanja.

Dengan hadirnya toko-toko online tentu seolah membawa angin surga bagi para wanita. Mereka bisa tetap eksis belanja tanpa merasa lelah atau menghabiskan waktu di pusat perbelanjaan. Selain lebih praktis, mudah, dan juga hemat karena tidak perlu keluar biaya 


\section{Jurnal Ilmiah Komunikasi}

transportasi atau makan akibat kelelahan berkeliling mall.

Penelitian terbaru AdWeek menunjukan bahwa mereka menemukan beberapa hal menarik, terutama yang berkaitan dengan bagaimana wanita berbelanja secara online. Penelitian ini melibatkan 11.000 pengguna internet wanita berusia 18 tahun ke atas. Penelitian tersebut menemukan bahwa; (1) $94 \%$ atau 10.340 wanita terlibat untuk online shopping secara aktif di internet, (2) $31 \%$ atau 3.410 wanita berinteraksi/mencari barangbarang yang ingin dibelanjakan secara online setiap harinya, (3) 90\% atau sekitar 9.900 wanita lebih suka online shopping menggunakan ponselnya, (4) $53 \%$ atau 5.830 wanita melakukan online shopping lewat laptop. ${ }^{5}$

Fenomena maraknya bisnis e-commerce dan tingginya presentase wanita gemar berbelanja online ini membuat penulis tertarik untuk menjadikannya sebagai objek penelitian. Berdasarkan paparan diatas, maka penulis tertarik untuk melakukan penelitian tentang strategi komunikasi pemasan Qoo10 Indonesia untuk tetap eksis di dunia bisnis e-commerce Indonesia. Disini penulis tertarik untuk melihat strategi komunikasi pemasaran Qoo10 Indonesia dalam memasarkan produk kategori fashionbeauty.

\section{Metode}

Secara etimologi metode berarti teknik atau cara. Penelitian ini merupakan penelitian deskriptif kualitatif. Jenis ini hanya terbatas pada bahasan untuk menggambarkan suatu masalah, keadaan atau peristiwa secara obyektif, sistematis dan cermat sebagaimana adanya keadaan yang sebenarnya terhadap obyek tersebut, sehingga bersifat analisis dalam mengungkapkan fakta keadaan sebenarnya. Penulis dalam hal ini bertindak hanya sebagai pengamat. ${ }^{6}$

Penelitian ini menggunakan variabel data kualitatif yang tidak menggunakan angka-angka tetapi dalam bentuk kategorikal. Kategorikal ini bersifat exhaustive. Artinya semua unsur harus mencakup semua kemungkinan yang ada. Variabel kualitatif adalah variabel yang menyatakan kualitas tertentu dari suatu data yang diamati dalam melakukan suatu penelitian. $^{7}$

Sumber data yang digunakan penulis ialah menggunakan Observasi partisipatif dan wawancara mendalam (depth interview). Observasi adalah suatu kegiatan mencari data yang dapat digunakan untuk memberikan suatu kesimpulan atau diagnosis. Metode Observasi adalah metode dimana peneliti mengamati langsung objek yang diteliti, sedangkan Observasi Partisipan adalah peneliti ikut berpartisipasi sebagai anggota kelompok yang diteliti.

Dalam penelitian ini, penulis melakukan wawancara kepada pihak-pihak (key informant) yang berkompeten untuk diwawancarai dalam hal perencanaan dan pelaksanaan strategi komunikasi pemasaran Qoo10 Indonesia yaitu Fashion-Beauty Merchandiser Manager/Group Leader dan Fashion-Beauty Promotion Marketing Leader. Penulis juga melakukan wawancara kepada saudari salah satu customer Qoo10 Indonesia yang sudah cukup sering berbelanja disana. Adapun pendekatan yang digunakan dalam penelitian ini dengan menggunakan pendekatan kualitatif, yaitu data yang terbentuk berupa uraian kata-kata ataupun lampiran untuk dikumpulkan dan kemudian dilakukan analisa secara deskriptif.

Dalam penelitian ini, penulis juga melakukan Depth Interview yang mana peneliti melakukan kegiatan wawancara tatap muka secara mendalam dan terus menerus untuk menggali informasi dari informan. Metode Depth interview tidak jarang digabung dengan metode observasi partisipan. Kedua metode tersebut merupakan wujud dari pendekatan konstruktivis, yaitu menganggap bahwa realitas ada dalam pikiran subjek yang diteliti. ${ }^{8}$

Data Primer penulis peroleh dari wawancara kepada narasumber yang berkompeten. Penulis memperoleh data dari hasil wawancara dengan orang - orang yang berhubungan langsung dengan pengambil keputusan mengenai strategi komunikasi pemasaran lebih khususnya dan melakukan pengamatan pada perusahaan yang menjadi obyek penelitian. 
Data Sekunder; yang merupakan data-data yang diperoleh peneliti dari studi pustaka atau data primer yang telah diolah lebih lanjut dan disajikan dalam bentuk tabel atau artikel yang berhubungan dengan karya ilmiah yang dibuat. Penulis mempelajari dan mengambil bahan studi pustaka, dokumen-dokumen perusahaan dalam masalah yang berkaitan langsung dengan informasi tentang perusahaan yang menjadi objek dalam penelitian.

Berdasarkan data yang diperoleh dari hasil wawancara dengan narasumber, pengamatan, dokumen perusahaan dan juga bulletin serta lainnya, selanjutnya penulis akan mendeskripsikan dan menjabarkan data tersebut secara kualitatif sesuai dengan fakta yang ada dengan terlebih dahulu melalui proses pengolahan data yang dilakukan penulis.

Dalam penelitian ini, penulis membahas tujuan-tujuan dari penelitian sendiri dengan menjabarkan secara terperinci dan terarah sesuai dengan yang sebenarnya. Dalam hal ini penulis ingin mengetahui bentuk strategi komunikasi pemasaran yang digunakan Qoo10 Indonesia agar bisa mempertahankan eksistensi di dunia ecommerce Indonesia. Dalam hal ini penulis merinci sebagai berikut :

Strategi komunikasi pemasaran merupakan perencanaan secara cermat mengenai pemasaran sebagai usaha menyampaikan pesan kepada publik terutama konsumen sasarannya mengenai keberadaan produk dipasar melalui bauran promosi dan menganalisa segmentasi, targeting dan posisioning serta mengaitkan karakteristik yang dimiliki produk agar tercapai tujuan-tujuan khusus yang diinginkan.

\section{Hasil dan Pembahasan}

Strategi berkaitan dengan arah tujuan dan kegiatan jangka panjang suatu organisasi. Strategi komunikasi pemasaran merupakan hal yang berkaitan dengan masalah perencanaan, pelaksanaan dan pengendalian komunikasi persuasive dengan khalayak sasaran.

Perkembangan di industri e-commerce sekarang meningkat dengan pesat, hal ini dapat di buktikan dari banyaknya kemunculan berbagai e-commerce, dan tentunya ada nya peningkatan banyaknya e-commerce yang terfokus pada bidang Fashion-Beauty. Hal ini membuat para pebisnis berlomba-lomba untuk menentukan strategi apa lagi yang harus dipakai agar produknya dapat diterima dengan baik di pasaran dan menciptakan suatu kondisi pasar yang kondusif dan terciptanya efektivitas akan strategi tersebut. Tidak terkecuali upaya yang dilakukan oleh Qoo10 khususnya dalam kategori Fashion-Beauty ini.

Untuk menemukan strategi yang paling pas diterapkan, Qoo10 Indonesia melakukan Strategi Pemasaran Modern yaitu STP (Segmenting, Targeting, dan Positioning) terlebih dahulu. ${ }^{9}$

STP menjelaskan mengenai proses pemasaran untuk membagi segmentasi pasar yang berbeda-beda. Setelah segmentasi, maka perusahaan dapat memilih segmen mana yang tepat bagi mereka (targeting), dan memilih cara yang tepat agar produk dapat diterima oleh segmen yang telah dipilih sebelumnya (positioning).

Segmenting atau segmentasi yang merupakan proses mengkotak-kotakkan pasar (yang heterogen) menjadi kelompok-kelompok yang memiliki kesamaan kebutuhan atau kesamaan karakter yang memiliki respons yang sama dalam membelanjakan uangnya. ${ }^{10}$

Adapun tiga pola segmentasi pasar yang dapat digunakan adalah: (1) Homogeneus Preference (preferensi homogen) ; merupakan pola yang menunjukkan bahwa konsumen memiliki preferensi yang sama terhadap produk atau jasa yang ditawarkan. (2) Diffused Preference (preferensi yang menyebar) ; menunjukkan bahwa konsumen memiliki preferensi yang beragam terhadap suatu produk atau jasa yang ditawarkan. (3) Clustered Preference (preferensi yang mengelompok) ; merupakan pola yang menunjukan bahwa konsumen memiliki referensi yang berkelompok-kelompok, dimana konsumen yang berada satu kelompok memiliki kesamaan preferensi.

Dari hasil penelitian ini, didapatkan bahwa pengguna situs terbesar Qoo10 Indonesia adalah Perempuan dengan range usia 25-34 tahun. Jika dilihat berdasarkan identifikasi geografis Qoo10 Indonesia, yang penulis berhasil dapatkan dari 


\section{Jurnal Ilmiah Komunikasi}

data perusahaan, Qoo10 Indonesia memiliki pasar yang lumayan baik di 5 negara, yaitu Indonesia, Singapura, Malaysia, Jepang, dan Korea. Sedangkan didalam negeri sendiri, yaitu Indonesia, Qoo10 Indonesia memiliki pasar yang baik di Jakarta, kemudian diikuti oleh Bekasi, lalu Depok. Jika dilihat berdasarkan segmen profesi pengguna Qoo10 Indonesia, yang penulis kembali dapatkan dari data perusahaan, hasilnya diduduki oleh karyawan / karyawati di urutan pertama, lalu diikuti ibu rumah tangga dan mahasiswa / pelajar.

Targeting merupakan proses pengevaluasian segmentasi dan pemfokusan strategi pemasaran pada suatu negara, propinsi, atau sekelompok yang memiliki potensi untuk memberikan respons. Targeting adalah mengevaluasi daya tarik tiap-tiap segmen, dan memilih satu atau lebih segmen yang akan dimasuki.

Dari hasil penelitian ini didapati informasi bahwasannya target market dari Qoo10 Indonesia untuk kategori Fashion-Beauty sebagai berikut; (1) Wanita (tapi tidak menutup kemungkinan Pria) usia 20 - 40 tahunan. (2) Tinggal di kota-kota besar di Indonesia, dan sangat memperhatikan penampilan.

Karyawan / Karyawati, Ibu Rumah Tangga, dan Mahasisa / Pelajar. (4) Kelas Menengah sampai Kelas Menengah ke Atas.

Tahap positioning dilakukan setelah menentukan strategi segmentasi yang akan digunakan. Dapat dikatakan positioning adalah suatu tindakan langkah-langkah dari produsen untuk mendesain citra perusahaan dan penawaran nilai dimana konsumen didalam suatu segmen tertentu mengerti dan menghargai apa yang dilakukan suatu segmen tertentu, mengerti dan menghargai apa yang dilakukan suatu perusahaan, dibandingkan dengan pesaing.

Setelah target market ditentukan, maka hal yang selanjutnya dilakukan adalah menentukan positioning dari perusahaan. Positioning pada dasarnya adalah suatu strategi untuk menanamkan citra produk di benak konsumen. Positioning saat ini menjadi sangat penting karena persaingan yang terjadi sudah sangat sengit, dimana semua produk pasti akan memiliki pesaing yang memiliki kualitas maupun atribut yang hampir sama. Apabila produk tidak memiliki positioning yang kuat, maka produk tersebut akan tidak terlihat ditengah timbunan produk yang sejenis.

Dari hasil penelitian ini, didapati bahwasannya Positioning dari Qoo10 Indonesia adalah ingin dinilai sebagai e-commerce yang bagus dan terpercaya yang memiliki produkproduk dengan harga termurah dibandingkan dengan e-commerce yang lain. Qoo10 Indonesia berusaha untuk menciptakan positioning sebagai e-commerce yang terpercaya adalah dengan menyediakan barang-barang yang berkualitas, dengan harga yang sangat terjangkau.

Perkembangan di industri e-commerce sekarang meningkat dengan pesat, hal ini dapat di buktikan dari banyaknya kemunculan berbagai e-commerce, dan tentunya ada nya peningkatan banyaknya e-commerce yang terfokus pada bidang Fashion-Beauty. Hal ini membuat para pebisnis berlomba-lomba untuk menentukan strategi apa lagi yang harus dipakai agar produknya dapat diterima dengan baik di pasaran dan menciptakan suatu kondisi pasar yang kondusif dan terciptanya efektivitas akan strategi tersebut. Tidak terkecuali upaya yang dilakukan oleh Qoo10 khususnya dalam kategori Fashion-Beauty ini.

Qoo10 sendiri memahami bahwa mereka tidak bisa sepenuhnya menguasai bisnis ecommerce ini dikarenakan banyaknya kompetitor, tetapi Qoo10 telah memiliki pasarnya sendiri.

Strategi Pemasaran Modern ini sangat membantu Qoo10 untuk membuat strategi pemasarannya. Dari hasil penelitian ini, diketahui bahwasannya strategi pesan Qoo10 Indonesia adalah berupaya untuk selalu memberikan penjelasan yang lengkap dan menarik di dalam tampilan item page website mereka; setiap item yang di promosikannya, mereka juga membuat desain-desain banner yang menarik agar calon konsumen tergugah untuk meng-klik item tersebut dan membelinya. Sedangkan untuk strategi media-nya sendiri, Qoo10 lebih mengedepankan dan mengoptimalkan promosi melalui media internal channel yang mereka miliki. 


\section{Jurnal Ilmiah Komunikasi}

Qoo10 tidak menggunakan media TVC ataupun media-media Above the Line sebagai salah satu strategi komunikasi pemasarannya. Dalam penggunaan pesan media, Qoo10 lebih menggunakan social media yang notabene gratis, dan mereka menggunakan Yahoo partnership, Google Ads Word, dan Email Blast sebagai strategi komunikasi pesan media berbayar mereka. Mengetahui demand pasar adalah salah satu kunci strategi komunikasi pemasaran yang penting bagi Qoo10. Pemilihan item yang bagus yang sedang diinginkan pasar dengan harga yang paling kompetetif merupakan salah satu strategi komunikasi pemasaran Qoo10 Indonesia. Guna mendukung bisnisnya, Qoo10 tetap menjaga kepercayaan konsumen dan eksklusifitas produk-produknya yang affordable, dengan kata lain, harga produknya boleh murah, tapi citranya tidak terlihat "murahan".

Dalam pelaksanaan kegiatan periklanan Qoo10 Indonesia menggunakan media elektronik. Qoo10 Indonesia menggunakan media iklan elektronik berupa media internet. Internet mempunyai kelebihan berupa dapat menjangkau konsumen yang sangat luas dan dengan jangka waktu yang tidak dibatasi secara khusus sehingga konsumen dapat mengakses informasi seputar perusahaan dan produk secara real time atau 24 jam penuh.

Qoo10 Indonesia ber partnership dengan Yahoo untuk mengiklankan websitenya. Berikut penampilan contoh iklan Qoo10 Indonesia di laman Yahoo. Selain itu, Qoo10 Indonesia juga menggunakan Google Display Network dan Search Ads (Keywords Bidding).

Jenis kegiatan publisitas yang dilakukan oleh Qoo10 Indonesia adalah menggunakan blogger-blogger yang sudah cukup terkenal untuk mempublikasikan website Qoo10 Indonesia.

Promosi penjualan yang dilakukan oleh Qoo10 Indonesia yaitu promosi penjualan bagi konsumen, yang memiliki kegunaan untuk meningkatkan penjualan terhadap produk yang ditawarkan. Promosi penjualan yang dilakukan oleh Qoo10 Indonesia biasanya adalah pemberian kupon potongan harga yang bisa customer akses di laman Qoo10 Indonesia. Tidak hanya itu, Qoo10 Indonesia juga seringkali memberikan penawaran free shipping, bundling promo, dan get free items.

Jenis kegiatan pemasaran langsung (Direction Marketing) yang dilakukan oleh Qoo10 Indonesia adalah dengan memanfaatkan internal channels yang telah mereka miliki, yaitu; On-Site Deals, Edms, Themed Promos, Push Notifications, Mobile Banner, dan Brand Zone.

Qoo10 juga menggunakan email blast yang dilakukan sehari 4 kali kepada para customer yang telah mendaftarkan diri (register) pada website Qoo10 Indonesia. Email berisi tentang penawaran-penawaran ataupun promosi terbaru dari Qoo10 Indonesia. Dengan begitu, para customer tidak perlu takut untuk ketinggalan informasi terbaru dari Qoo10 Indonesia. Qoo10 Indonesia juga memiliki Social Media Fan Page untuk memudahkan para customer agar selalu dapat mengupdate promosi terbaru Qoo10 Indonesia.

Strategi Komunikasi Pemasaran yang dilakukan oleh Qoo10, bukanlah sesuatu yang baku, Qoo10 selalu mereview hasil daripada implementasi strategi komunikasi pemasaran mereka setiap 6 bulan sekali. Produk kategori Fashion-Beauty sendiri terbagi menjadi 4, yaitu; Fashion Major, Apparel, BSA (Bags - Shoes Accessories) \& Sports, dan Beauty \& Cosmetics. Dari hasil penelitian didapatkan bahwasannya, kategori Beauty-Cosmetics selalu yang menjadi andalan dalam beberapa waktu belakangan (2015-2017).

Dari hasil penelitian, ditemukan bahwa hasil implementasi strategi komunikasi pemasaran kategori Fashion-Beauty Qoo10 Indonesia periode Januari - Juni 2017, adalah sebagai berikut; Beauty \& Cosmetics memimpin dengan perolehan cart terbesar yaitu 20.457 cart pada Juli 2017, selanjutnya diikuti oleh Apparel diurutan kedua dengan total 14.567 cart, kemudan Fashion Major dengan total 13.854 cart, dan terakhir Bags -Shoes - Accessories diurutan terakhir dengan perolehan cart 8.457, yang mana semuanya ada di bulan Juni 2017.

Dari hasil penelitian didapatkan bahwa penjualan Qoo10 kategori Fashion-Beauty meningkat dari periode sebelumya, dengan top 5 


\section{Jurnal Ilmiah Komunikasi}

item yang didominasi oleh tim BeautyCosmetics.

Strategi Qoo10 yang selalu berubah, mengikuti keinginan dan demand pasar-lah yang membuat Qoo10 bisa tetap eksis. Qoo10 Indonesia memang tidak seterkenal e-commerce yang lainnya, tetapi Qoo10 Indonesia telah memiliki tempat tersendiri oleh customernya dan juga calon customer.

\section{Kesimpulan}

Berdasarkan hasil penelitian, maka ditemukan kesimpulan bahwa Qoo10 Indonesia telah menyampaikan strategi komunikasi pemasarannya melalui beberapa bauran komunikasi pemasaran. Qoo10 Indonesia yang berperan sebagai komunikator berusaha melakukan beberapa strategi pesan yang ingin disampaikan kepada konsumennya. Pesan dibuat sedemikian mungkin, yang berisikan informasi mengenai setiap produk yang dipromosikan. Pesan dibuat dengan menggunakan desain yang eye-catching, untuk menarik calon pembeli.

Qoo10 Indonesia selalu memberikan description yang yang lengkap di setiap item page dan banner utama produk yang dijual dan di promosikan dengan desain yang sedemikian menarik, agar calon konsumen tertarik untuk meng-klik banner dan membeli produk tersebut.

Qoo10 Indonesia juga sering memberikan promosi (sales promotion) rutin berkala berupa kupon potongan harga yang bisa didapatkan di laman web-nya. Qoo10 Indonesia juga sering memberikan promosi berupa buy 1 get 1 free, free shipping, dan harga minus kepada konsumennya.

Qoo10 Indonesia memaksimalkan internal channel yang mereka miliki. Qoo10 Indonesia menggunakan alat pemasarannya seperti On-Site Deals, Edms, Themed Promos, Push Notifications, Mobile Banner, Brand Zone, Email Blast, dan Social Media Fan Page dalam memasarkan secara langsung (direct marketing) kepada seluruh registered member dan customer mereka.

Selain itu, Qoo10 Indonesia juga selalu berusaha mendapat item-item yang akan dipromosikan sesuai demand pasar dan sesuai dengan apa yang akan "in" dengan harga yang cenderung murah dibanding kan e-commerce lain. Qoo10 Indonesia selalu berupaya untuk mempertahankan citra perusahaan sebagai ecommerce yang yang murah dengan kualitas tidak "murahan".

\section{Saran}

Berdasarkan hasil penelitian, peneliti memberikan saran kepada Qoo10 Indonesia untuk memulai melakukan periklanan dengan media Above the Line, baik berupa iklan Televisi, Billboard / Spanduk, Majalah, atau lainnya, mengingat sesama pesaingnya di dunia e-commerce memborbardir berbagai media above the line dengan iklan perusahaan mereka masing-masing; agar brand awareness Qoo10 Indonesia bisa tertanam lebih luas di benak masyarakat dengan kata lain lebih banyak lagi masyarakat yang mengenal Qoo10 Indonesia, dan bisa menggiring Qoo10 Indonesia menjadi e-commerce yang terdepan di Indonesia.

Disarankan juga kepada pihak Qoo10 Indonesia, untuk lebih selektif memilih produk yang akan dijual dan dipromosikan, agar produk-produk yang tidak original bisa lebih diawasi bahkan di take out dari laman website Qoo10 Indonesia. Qoo10 Indonesia diharapkan untuk bisa tetap menjaga imagenya sebagai $e$ commerce yang memiliki produk berkualitas dengan harga yang kompetetif (murah).

\section{Daftar Pustaka}

1. Barkatullah, Abdul Halim. Bisnis ECommerce, Yogyakarta: Pustaka Pelajar, 2015.

2. Maria, Ellsye. Strategi Komunikasi Pemasaran Bisnis Online Berbasis ECommerce (Studi Kasus Strategi Komunikasi Pemasaran Website www.bukalapak.com). Yogyakarta : Universitas Gajah Mada. 2016.

3. Hadi, Feryanto. Transaksi E-Commerce di Indonesia mencapai 4,89 Miliar Dolar AS (http://tribunnews.com) diakses 13 Januari 2018.

4. Raditya, D. 2013. Penanaman Modal Pasar Bisnis dalam E-Commerce: tidak diterbitkan. 


\section{Jurnal Ilmiah Komunikasi}

5. Viva. Alasan Wanita Gemar Berbelanja Online (http://viva.co.id) diakses 15 Januari 2018.

6. Lexy, Moleong J. Metode Penelitian Kualitatif, Bandung: PT: Remaja Roda Karya, 2014.

7. A. Shimp, Terence. Komunikasi Pemasaran Terpadu dalam periklanan dan Promosi. Jakarta: Salemba Empat, 2014.

8. Arikunto, Suharsimi. Metode Penelitian Suatu Tujuan Praktek. Penerbit Rineka Cipta. Jakart, 2016.
9. Pranoto, Amin. Strategi Komunikasi Pemasaran Dengan Media Internet Pada PT. Galang Mandiri. Jakarta : Universitas Mercu Buana. 2015.

10. Ariwibowo, Dwi Putra Jaya., dan Mahendra Adhi Nugroho. Pengaruh Trust Dan Perceived Of Risk Terhadap Niat Untuk Bertransaksi Menggunakan E-Commerce. Yogyakarta: Universitas Negeri Yogyakarta. 2015. 